Pacific Journal of Mathematics

RAMSEY BOUNDS FOR GRAPH PRODUCTS

EOS, ROBERT JAMES MCELIECE AND HERBERT TAYLOR 


\section{RAMSEY BOUNDS FOR GRAPH PRODUCTS}

\section{Paul ERdös, Robert J. McEliece and Herbert Taylor}

\section{Here we show that Ramsey numbers $M\left(k_{1}, \cdots, k_{n}\right)$ give} sharp upper bounds for the independence numbers of product graphs, in terms of the independence numbers of the factors.

The Ramsey number $M\left(k_{1}, \cdots, k_{n}\right)$ is the smallest integer $m$ with the property that no matter how the $\left(\begin{array}{c}m \\ 2\end{array}\right)$ edges of the complete graph on $m$ nodes are partitioned into $n$ colors, there will be at least one index $i$ for which a complete subgraph on $k_{i}$ nodes has all of its edges in the $i$ th color. Ramsey's Theorem tells that these numbers exist but only a few exact values are known.

The complement graph $\bar{G}$ has the same nodes as $G$ and the complementary set of edges.

The independence number $\alpha(G)$ of a graph $G$, is the largest number of nodes in any complete subgraph of $\bar{G}$.

The product $G_{1} \times \cdots \times G_{n}$ of graphs $G_{1}, \cdots, G_{n}$ is the graph whose nodes are all the ordered $n$-tuples $\left(a_{1}, \cdots, a_{n}\right)$ in which $a_{i}$ is a node of $G_{i}$ for each $i$ from 1 to $n$, and whose edges are as follows. A set of two nodes $\left\{\left(a_{1}, \cdots, a_{n}\right),\left(b_{1}, \cdots, b_{n}\right)\right\}$ will be an edge of $G_{1} \times \cdots \times G_{n}$ if and only if the nodes are distinct and for each $i$ from 1 to $n, a_{i}=b_{i}$ or $\left\{a_{i}, b_{i}\right\}$ is an edge of $G_{i}$.

THeOREM 1. For arbitrary graphs $G_{1}, \cdots, G_{n}$

$$
\alpha\left(G_{1} \times \cdots \times G_{n}\right)<M\left(\alpha\left(G_{1}\right)+1, \cdots, \alpha\left(G_{n}\right)+1\right) .
$$

Proof. We have a complete subgraph of $\overline{G_{1} \times \cdots \times G_{n}}$ on $\alpha\left(G_{1} \times \cdots \times G_{n}\right)$ nodes. Its edges can be $n$ colored by the following rule: give $\left\{\left(a_{1}, \cdots, a_{n}\right),\left(x_{1}, \cdots, x_{n}\right)\right\}$ color $i$ if $i$ is the first index for which $\left\{a_{i}, x_{i}\right\}$ is an edge of $\bar{G}_{i}$.

With this coloration any case where all the edges on $k$ nodes have color $i$ requires a complete $k$ subgraph of $\bar{G}_{i}$ and so requires $k<\alpha\left(G_{i}\right)+1$. With the definition of the Ramsey number this ensures that

$$
\alpha\left(G_{1} \times \cdots \times G_{n}\right)<M\left(\alpha\left(G_{1}\right)+1, \cdots, \alpha\left(G_{n}\right)+1\right) .
$$

THEOREM 2. If $k_{1}, \cdots, k_{n}$ are given, there exist graphs $G_{1}, \cdots, G_{n}$ such that for each index $i$ from 1 to $n, \alpha\left(G_{i}\right)=k_{i}$ and

$$
\alpha\left(G_{1} \times \cdots \times G_{n}\right)=M\left(k_{1}+1, \cdots, k_{n}+1\right)-1 .
$$


Proof. From the definition of the Ramsey number there must exist an $n$ color partition of the edges of the complete graph on $M\left(k_{1}+1, \cdots, k_{n}+1\right)-1=m$ modes such that for every $i$ from 1 to $n$ the largest complete subgraph in the $i$ th color is on $k_{i}$ nodes. For each $i$ let $G_{i}$ be the graph on the same $m$ nodes having all the edges not of color $i$. Thus for each $i, \alpha\left(G_{i}\right)=k_{i}$. These $G_{i}$ make the diagonal a complete $m$ subgraph of $\overline{G_{1} \times \cdots \times G_{n}}$, and so

$$
\alpha\left(G_{1} \times \cdots \times G_{n}\right) \geqq m .
$$

Applying Theorem 1 we have

$$
\alpha\left(G_{1} \times \cdots \times G_{n}\right)=M\left(k_{1}+1, \cdots, k_{n}+1\right)-1
$$

THEOREM 3. If $n$ and $k$ are given, there exists a graph $G$ such that $\alpha(G)=k$ and putting $k_{i}=k$ for every $i$,

$$
\alpha\left(G^{n}\right)=M\left(k_{1}+1, \cdots, k_{n}+1\right)-1 .
$$

Proof. With $m=M\left(k_{1}+1, \cdots, k_{n}+1\right)-1$ and every $k_{i}=k$, refer to the graphs $G_{1}, \cdots, G_{n}$ as specified for Theorem 2. Now construct $G$ as follows. Let the nodes of $G$ be all the ordered pairs $(a, i)$ such that $1 \leqq i \leqq n$ and $a$ is a node of $G_{i}$. Let $\{(a, i),(b, j)\}$ be an edge of $G$ if and only if $i \neq j$ or $\{a, b\}$ is an edge of $G_{i}$.

Thus constructed $\alpha(G)=k$ because each $\alpha\left(G_{i}\right)=k$. $\overline{G^{n}}$ will have a subgraph isomorphic to $\overline{G_{1} \times \cdots \times G_{n}}$ and consequently

$$
\alpha\left(G^{n}\right) \geqq \alpha\left(G_{1} \times \cdots \times G_{n}\right)=m .
$$

So again with Theorem 1 we have

$$
\alpha\left(G^{n}\right)=m=M\left(k_{1}+1, \cdots, k_{n}+1\right)-1 .
$$

A question remains whether for every $k, n$ with

$$
k^{2} \leqq n<M(k+1, k+1)
$$

there exists $G$ such that $\alpha(G)=k$ and $\alpha\left(G^{2}\right)=n$. It is known that $M(4,4)=18$, and for each $n$ between 9 and 17 we have found a graph $G$ such that $\alpha(G)=3$ and $\alpha\left(G^{2}\right)=n$. However it is only known that $37<M(5,5)<58$ and for example we have no proof that there exists a graph $G$ such that $\alpha(G)=4$ and $\alpha\left(G^{2}\right)=M(5,5)-2$.

Received May 25, 1970. The work of the latter two authors represents one phase of research carried out at the Jet Propulsion Laboratory, California Institute of Technology, under Contract No. NAS 7-100, sponsored by the National Aeronautics and Space Administration. 


\section{PACIFIC JOURNAL OF MATHEMATICS}

\section{EDITORS}

H. SAMELSON

Stanford University

Stanford, California 94305

C. R. Новву

University of Washington

Seattle, Washington 98105
J. DUGundJI

Department of Mathematics

University of Southern California

Los Angeles, California 90007

RICHARD ARENS

University of California

Los Angeles, California 90024

\section{ASSOCIATE EDITORS}
E. F. BECKENBACH
B. H. NeumanN
F. WOLF
K. YOSHIDA

\section{SUPPORTING INSTITUTIONS}
UNIVERSITY OF BRITISH COLUMBIA
CALIFORNIA INSTITUTE OF TECHNOLOGY
UNIVERSITY OF CALIFORNIA
MONTANA STATE UNIVERSITY
UNIVERSITY OF NEVADA
NEW MEXICO STATE UNIVERSITY
OREGON STATE UNIVERSITY
UNIVERSITY OF OREGON
OSAKA UNIVERSITY
UNIVERSITY OF SOUTHERN CALIFORNIA
STANFORD UNIVERSITY
UNIVERSITY OF TOKYO
UNIVERSITY OF UTAH
WASHINGTON STATE UNIVERSITY
UNIVERSITY OF WASHINGTON
AMERICAN MATHEMATICAL SOCIETY CHEVRON RESEARCH CORPORATION TRW SYSTEMS
NAVAL WEAPONS CENTER 


\section{Pacific Journal of Mathematics}

\section{Vol. 37, No. $1 \quad$ January, 1971}

Gregory Frank Bachelis and Haskell Paul Rosenthal, On unconditionally

converging series and biorthogonal systems in a Banach space .........

Richard William Beals, On spectral theory and scattering for elliptic

operators with singular potentials .........................

J. Lennart (John) Berggren, Solvable and supersolvable groups in which every element is conjugate to its inverse ........................ 21

Lindsay Nathan Childs, On covering spaces and Galois extensions ..........

William Jay Davis, David William Dean and Ivan Singer, Multipliers and

unconditional convergence of biorthogonal expansions..............

Leroy John Derr, Triangular matrices with the isoclinal property ............

Paul Erdős, Robert James McEliece and Herbert Taylor, Ramsey bounds for

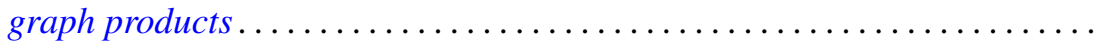

Edward Graham Evans, Jr., On epimorphisms to finitely generated

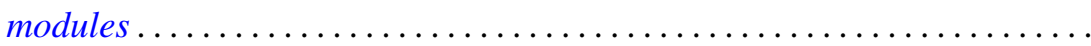

Hector O. Fattorini, The abstract Goursat problem ................. 51

Robert Dutton Fray and David Paul Roselle, Weighted lattice paths .........

Thomas L. Goulding and Augusto H. Ortiz, Structure of semiprime $(p, q)$

radicals ...........................................

E. W. Johnson and J. P. Lediaev, Structure of Noether lattices with join-principal maximal elements ....

David Samuel Kinderlehrer, The regularity of minimal surfaces defined over

slit domains

Alistair H. Lachlan, The transcendental rank of a theory. .

Frank David Lesley, Differentiability of minimal surfaces at the boundary ...

Wolfgang Liebert, Characterization of the endomorphism rings of divisible torsion modules and reduced complete torsion-free modules over complete discrete valuation rings....

Lawrence Carlton Moore, Strictly increasing Riesz norms.

Raymond Moos Redheffer, An inequality for the Hilbert transform ...

James Ted Rogers Jr., Mapping solenoids onto strongly self-entwined,

circle-like continua..........................

Sherman K. Stein, B-sets and planar maps ................... 217

Darrell R. Turnidge, Torsion theories and rings of quotients of Morita

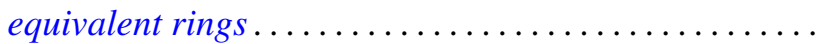

Fred Ustina, The Hausdorff means of double Fourier series and the principle of localization ................................

Stanley Joseph Wertheimer, Quasi-compactness and decompositions for arbitrary relations.

Howard Henry Wicke and John Mays Worrell Jr., On the open continuous images of paracompact $\check{C}$ ech complete spaces... 